\title{
MicroRNAs regulate granulosa cells apoptosis and follicular development - A review
}

\author{
Zhuandi Gong', Juan Yang ${ }^{2}$, Shengju Bai', and Suocheng Wei ${ }^{2, *}$
}

\author{
* Corresponding Author: Suocheng Wei \\ Tel: +86-931-2938120, Fax: +86-931-2938120, \\ E-mail:weisc668@163.com \\ ${ }^{1}$ Hospital, Northwest Minzu University, Lanzhou \\ 730030, China \\ ${ }^{2}$ College of Life Science and Engineering, Northwest \\ Minzu University, Lanzhou 730030, China \\ ORCID \\ Zhuandi Gong \\ https://orcid.org/0000-0003-3929-1493 \\ Juan Yang \\ https://orcid.org/0000-0002-4829-2888 \\ Shengju Bai \\ https://orcid.org/0000-0001-7262-0944 \\ Suocheng Wei \\ https://orcid.org/0000-0002-1480-1832
}

Submitted Sept 7, 2019; Revised Oct 31, 2019; Accepted Dec 9, 2019
Objective: MicroRNAs (miRNAs) are the most abundant small RNAs. Approximately 2,000 annotated miRNAs genes have been found to be differentially expressed in ovarian follicles during the follicular development (FD). Many miRNAs exert their regulatory effects on the apoptosis of follicular granulosa cells (FGCs) and FD. However, accurate roles and mechanism of miRNAs regulating apoptosis of FGCs remain undetermined.

Methods: In this review, we summarized the regulatory role of each miRNA or miRNA cluster on FGCs apoptosis and FD on the bases of 41 academic articles retrieved from PubMed and web of science and other databases.

Results: Total of 30 miRNAs and 4 miRNAs clusters in 41 articles were reviewed and summarized in the present article. Twenty nine documents indicated explicitly that 24 miRNAs and miRNAs clusters in 29 articles promoted or induced FGCs apoptosis through their distinctive target genes. The remaining 10 miRNAs and miRNAs of 12 articles inhibited FGCs apoptosis. MiRNAs exerted modulation actions by at least 77 signal pathways during FGCs apoptosis and FD.

Conclusion: We concluded that miRNAs or miRNAs clusters could modulate the apoptosis of GCs (including follicular GCs, mural GCs and cumulus cells) by targeting their specific genes. A great majority of miRNAs show a promoting role on apoptosis of FGCs in mammals. But the accurate mechanism of miRNAs and miRNA clusters has not been well understood. It is necessary to ascertain clearly the role and mechanism of each miRNA or miRNA cluster in the future. Understanding precise functions and mechanisms of miRNAs in FGCs apoptosis and FD will be beneficial in developing new diagnostic and treatment strategies for treating infertility and ovarian diseases in humans and animals.

Keywords: microRNAs; Apoptosis; Granulosa Cells; Cumulus Cells; Follicular Development

\section{INTRODUCTION}

The first microRNA (miRNA) was discovered in the Caenorhabditis elegans by Ambros and Ruvkun in 1993 [1]. Later, a lot of miRNAs were discovered in human and animals [2]. The miRNAs are originally transcribed from coding genes which occupy $1 \%$ to $3 \%$ of the genome. Currently, approximately 2,000 annotated miRNAs have been reported in humans $[3,4]$. The miRNAs regulate about $30 \%$ of protein-coding genes in mammals since the different miRNAs may target the same mRNAs [5]. Nucleotides sizes of miRNAs are differentially reported in the mammals, including 19 to 22 nucleotides [6], 20 to 24 nucleotides [6,7], 21 to 23 nucleotide [4], and even 21 to 26 molecules [8]. Consequently, the precise numbers of nucleotides of miRNAs remain undetermined $[9,10]$.

Roughly, 52\% of human miRNAs are localized within the intergenic regions, $40 \%$ are located within intronic regions, and the rest $8 \%$ are situated within exons [11]. In mammals, most miRNAs regulate gene expression via combining the $3^{\prime}$-untranslated region (UTR) 
and the specific sequences of target mRNAs, causing repression of translation of target mRNAs [12-14]. One miRNA may target hundreds of different mRNAs. However, the regulatory mechanism of every miRNA remains unclearly understood [12].

Follicular granulosa cells (FGCs) play a key role in nourishing oocytes through secreting growth factors and hormones and regulating development of oocytes [15]. It has been well known that miRNAs exert the vital functions in FGCs apoptosis and follicular development (FD) $[8,16,17]$. The functions of specific miRNAs are implicated in different aspects of FGCs processes of the mammals, such as proliferation [18], differentiation [19], and cumulus expansion [20].

Previous studies aimed to determine the roles of miRNAs on the FD of mammals using various approaches, including conditional knockout of miRNA biogenesis genes, highthroughput sequencing technologies in various animal models. Nowadays, it has been well known that miRNAs exert a significant role in FD and oocyte development of mammals $[8,21]$.

However, so far the accurate effects and regulatory mechanism of different miRNAs regulating apoptosis of granulosa cells (GCs) and FD have still remained unclear, especially their target genes and signaling pathways $[20,22]$. The present review aimed to comprehensively elaborate the research advances on miRNAs for modulating apoptosis of FGCs and FD in humans and animals so as to seek new diagnostic and treatment scheme for infertility and ovarian diseases.

\section{miRNAs MODULATE APOPTOSIS OF FOLLICULAR GRANULOSA CELLS}

The miRNAs regulate the function of FGCs via altering expression levels of target genes [7,23]. The microRNA (miR)let-7 family is highly conserved in sequences across animal species. MiR-let-7 family is differentially expressed during follicular atresia [24]. Expression levels of miR-let-7a, let-7b, let-7c, and let-7i genes were reduced in early and progressed atretic follicles as compared to those in healthy follicles $[25,26]$. The miR-let-7g-mediated suppression of mitogen-activated protein kinase kinase kinase 1 (MAP3K1) resulted in the expression and dephosphorylation of the transcription factor fork head O1 (FOXO1) which induced FGCs apoptosis [27]. Overexpression of miR-let-7g increased the apoptosis rate of the mouse FGCs [26] and FOXO1 expression in FGCs, and then resulted in nuclear accumulation of dephosphorylated FOXO1. Additionally, the expression levels of the apoptosisassociated genes including Caspase 3, BCL2-Associated X $(B A X)$, and BES1-interacting Myc-like protein $(B I M)$ were significantly upregulated after miR-let-7g mimic was transfected into porcine FGCs. But the anti-apoptotic genes B-cell lymphoma-2 (Bcl-2) and myeloid cell leukemia-1 were sig- nificantly down-regulated [26]. Briefly, the miR-let-7 family exerted a potential in the regulation of FGCs apoptosis.

MiR-21 is one of three highly luteinizing hormone (LH) -induced miRNAs in murine FGCs [14]. It acts as an antiapoptotic factor in GCs. A loss of miR-21 in vivo leads to a reduction of ovulation rates [28]. MiR-21 blocks the apoptosis of murine FGCs [14,29]. Several miR-21 target transcripts have been identified to explain its antiapoptotic effect, including programmed cell death 4 , phosphatase and tensin homologue $[29,30]$.

The levels of the primary transcript of miR-21 (pri-miR-21) and mature miR-21 were obviously increased in the cumulus oocyte complexes (COCs) over the maturation period. The pri-miR-21 expression was remarkably decreased in COCs treated with a signal transducer and activator of transcription 3 pathway inhibitor, and cumulus expansion may be prevented. Inihibition of Pri-miR-21 expression directly influenced miR-21 expression in bovine oocytes and cumulus cells (CCs) [31]. Upregulating miR-21 expression significantly reduced CCs apoptosis. The oocyte-secreted factors (OSFs) upregulated miR-21 expression and suppressed FCCs apoptosis by activating the PI3K/Akt signal [29]. It is known that oocytes and CCs are more resistant to apoptosis than other compartments of the antral follicle. However, little is known about the intracellular mechanisms by which OSFs render FCCs resistant to apoptosis [29,32].

MiR-146a is implicated in ovarian cancer development by suppressing the expression of antiapoptotic genes, such as $\mathrm{X}$ linked inhibitor of apoptosis protein, $\mathrm{Bcl}-2$-like protein 2, and baculoviral IAP repeat containing 5 [33]. The downregulation of miR-146a inhibited apoptosis of FGCs by simultaneously targeting interleukin-1 receptor-associated kinase (IRAK1) [34]. A recent study demonstrated that miR-126 inhibited FSH receptor (a direct target gene) expression and increased the apoptosis rate of porcine FGCs [35]. However, the cell apoptosis rate was dramatically reduced when miR-141-3p was overexpressed in rat FGCs [36].

An earlier report revealed that miR-26b enhanced DNA breaks and FGCs apoptosis by targeting the ataxia telangiectasia mutated (ATM) gene [37]. Overexpression of miR-26b promoted porcine FGCs apoptosis by regulating the expression of Sma-and Mad-related 4 (SMAD4). These results strongly suggest that miR-26b plays a crucial role in FGCs apoptosis [37]. MiR-125b regulated apoptosis by targeting bone morphogenetic protein receptor $1 \mathrm{~B}(B M P R 1 B)$ in yak FGCs [38].

The miR-144 was differentially expressed in the porcine preovulatory follicles. The miR-144 regulated FGCs apoptosis and affected follicular atresia [39]. Additionally, miR-224 was involved in the mouse FGCs proliferation via targeting SMAD4 [33]. Another study indicated that miR-1275 was expressed during the porcine follicular atresia. The miR-1275 
can promote early apoptosis of porcine FGCs and the initiation of follicular atresia (FA) by inhibiting estradiol release and expression of liver receptor homolog (LRH)-1 that was bound to the cytochrome P450, family 19, subfamily A, polypeptide 1 promoter and increased its activity. Additionally, miR-1275 attenuated $L R H-1$ expression by directly binding to its 3' UTR [40].

\section{MiRNAs REGULATE DEVELOPMENT OF MURAL GCs AND CUMULUS CELLS}

The GCs are divided and differentiated into mural GCs and CCs that tightly surround the oocyte $[41,42]$. Both mural GCs and CCs are two specialized cell types that differentiate from a common progenitor during folliculogenesis [43]. Mural FGCs supported the oocytes via endocrine and paracrine pathways [44]. The miRNAs are differentially expressed between CCs and mural GCs [45]. Another report showed that 59 miRNAs were found differentially expressed between bovine immature and maturated oocytes [46]. The sequencing analysis revealed the expression of several hundreds of miRNAs in mural GCs and CCs. 53 miRNAs (such as miR146a-5p, miR-149-5p, miR-509-3p, and miR-182-5p) were differentially expressed between mural FGCs and CCs [43]. Top 10 most abundant miRNAs in mural GCs and CCs were miR-21-5p, let-7a-5p, let-7f-5p, miR-26a-5p, let-7b-5p, let-7g-5p, miR-103a-3p, miR-125a-5p, miR-92a-3p, miR$320 \mathrm{a}$, and other miRNAs. MiR-146a-5p, miR-182-5p, miR509-3p, and miR-149-5p exert their regulatory functions through 37, 43, 2, and 9 target genes, respectively [43].

Expression of miR-130b was altered during oocyte maturation by directly targeting SMAD5 and mitogen- and stressactivated protein kinase 1 which were identified as target genes of miR-130b. Overexpression of miR-130b increased the proliferation of mural GCs and CCs. But, inhibition of miR-130b expression during in vitro maturation (IVM) of oocytes decreased the first polar body extrusion and the mitochondrial activity. Such, functional modulation of miR-130b affected the proliferation and survival of GC and CC as well as oocyte maturation [47].

Previous studies also demonstrated miR-146a-5p promoting apoptosis of mural GCs by directly targeting IRAK1 and tumor necrosis factor receptor-associated factor 6 and miR503-5p inhibiting proliferation by targeting cyclin D2 [48]. In 9 differentially expressed miRNAs, 4 miRNAs (hsa-miR146a-5p, has-miR-10b-5p, hsa-miR-29b-3p, and hsa-miR-142$5 p$ ) in mural GCs, and 5 miRNAs (hsa-let-7c-5p, hsa-miR125b-5p, hsa-miR-1275, hsa-miR-129-5p, and hsa-miR-129$2-3 p)$ in CC were upregulated [43].

Overall together, studies on cell communication, extracellular matrix and signaling pathways have demonstrated the differential expressions of miRNAs have relevance with physi- ological functions of CCs and mural GCs [45].

\section{MiRNAs REGULATE DEVELOPMENT OF OVARIAN FOLLICLES}

Both FD and oocyte maturation are completed in the ovaries of female mammals. A highly complicated, spontaneous death phenomenon that is called as atresia takes place during the FD and maturation in the mammals. Follicular atresia is resulted from the apoptosis of GCs surrounding oocytes [49]. In mammals, less than $1 \%$ of ovarian follicles will eventually ovulate. More than $99 \%$ of ovarian follicles are disappeared as a result of atresia, which affects all stages of follicular growth and development [50].

The FD is mediated by various regulatory factors including many miRNAs [51]. Numerous miRNAs play important roles in follicular atresia and development $[49,52]$. The miRNAs exert their functions as mediators of these processes via their extensive involvement in post-transcriptional mRNA regulation $[53,54]$. The miRNAs are differentially expressed during the primordial development [55], luteal development [56] and the whole FD [54].

MiR-378 could affect oocyte IVM by inhibiting the expansion and altering gene expression of CCs, and adjust in estradiol production by depressing aromatase translation in porcine FGCs. The miR-378 decreased IVM rate, suppressed the expression of genes associated with FD, such as bone morphogenetic protein 15 and growth differentiation factor 9 and also increased apoptosis rate [21] since miR-378 targeted to the 3'-UTR of aromatase mRNA [57].

MiR-23a and miR-27a have been reported to promote GC apoptosis by targeting SMAD5 through the FasL-Fas-mediated pathway $[8,58,59]$. Knocking down SMAD5 expression increased the rate of apoptosis [59]. Additionally, studies indicated miR-183-5p and miR-149-5p inhibit the release of progesterone and estradiol, respectively [17]. Moreover, miR509-3p promotes estradiol secretion by targeting MAP3K8 [60].

In summary, up to date many miRNAs mediate the process of oocyte maturation and folliculogenesis and also regulate follicular atresia through their target genes, thereby modulating FGCs apoptosis [59]. A large number of miRNAs and miRNA clusters involved in the FD have been documented [61-63]. However, accurate roles of miRNAs and miRNA clusters in this process are not clearly understood $[8,63]$. Understanding the miRNAs roles will elucidate clearly the mechanisms of GC apoptosis, development and atresia of ovarian follicles [64].

\section{MiRNA CLUSTERS REGULATE FGCs APOPTOSIS AND FOLLICULAR DEVELOPMENT}


A miRNA cluster comprises of more than two miRNAs with similar functions [65]. Currently, it has been reported that the specific miRNA families and clusters are involved in follicular atresia and development including miR-21, miR-23a, miR-145, miR-503, miR-224, miR-383, miR-378, miR-132, miR-212, the let-7 family, miR-17-92 cluster, miR-23-27-24 cluster, miR-183-96-182 cluster, miR-17-92 cluster and so on $[28,64,66,67]$. However, it has been undetermined which miRNA cluster(s) are associated with the each stage of FD $[61,63,64]$. Furthermore, actual roles of these miRNA clusters in the FD, atresia and ovulation remain unclear $[8,43,68]$.

Fifteen different miRNAs were found during the growth and selection of dominant follicles [69]. Six miRNAs, including miR-17, miR-18a, miR-19a, miR-20a, miR19b, and miR92a, are encoded by a single miR-17-92 transcript [70], and are expressed and processed together as a cluster [63]. The miR-17-92 cluster was differentially expressed in GCs from subordinate and dominant follicles at day 19 of the estrous cycle [71]. The overexpression of the miR-17-92 cluster promoted GC proliferation and reduced the proportion of differentiated cells. However, miR-17-92 cluster inhibition resulted in decreased proliferation and increased differentiation in GCs [71].

The miR-183-96-182 cluster (miR-183, miR-96, and miR182 ) is highly conserved [72], it is also abundantly expressed in both luteal cells and bovine FGCs of preovulatory dominant follicles $[20,73]$. This miRNAs cluster impacted bFGCs proliferation. The overexpression of miR-183-96-182 promoted the proliferation of bovine FGCs [20]. This cluster targeted the $3^{\prime}$-UTR of the FOXO1 gene [74], and thus regulated FD and luteal development via exerting effects on cell survival and steroid production. Moreover, it was also reported miR182 inhibited FGCs apoptosis by targeting SMAD7. However, the actual roles and mechanism of miRNAs remain to be comprehensively investigated in the FGCs apoptosis and follicular atresia $[8,75,76]$.

The miR-23-27-24 cluster comprises the miR-23a gene cluster (miR-23a, miR-27a, and miR-24-2 genes) and the miR23b cluster (mir-23b, mir-27b, and mir-24-1 genes) that exert their function via SMAD5. SMAD5 is a direct target of mir23a and mir-27a, which promote GC apoptosis via the FasFasL pathway [59]. These evidences suggest that miR-23-2724 clusters play a role in follicular atresia. On the other hand, expression levels of miR-23a-27a-24, miR-222-221, and miR214-199a clusters showed an increase until the mid-luteal phase, but expression decreased in the dominant FGCs during the late follicular phase of the estrous cycle.

The miR-17-92 cluster (including miR-17, miR-18a, miR19a, miR-19b, miR-20a, and miR-92a) was activated via direct binding the MYCN proto-oncogene/MYC proto-oncogene promoter $[64,77]$. This cluster showed to regulate the transforming growth factor $\beta$ (TGF $\beta$ ) pathway and affect FGCs apoptosis and follicular atresia [70]. Similarly, the miR-132212 cluster is associated with ovulation and was elevated after the induction with an ovulatory dose of $\mathrm{LH} /$ human chorionic gonadotropin [16], preventing cells from entering into apoptosis.

Based on the reported information in recent years, the regulatory roles of miRNAs on FGCs are summarized in Table 1. As presented in table 1 , in total of 41 academic theses regarding 34 miRNAs and miRNAs clusters that reported the regulatory effects of miRNAs on FGCs apoptosis in mammals. The documents indicated explicitly that 24 miRNAs and miRNAs clusters in 29 articles promoted or induced FGCs apoptosis through their distinctive target genes. Seven miRNAs inhibited FGCs apoptosis. So far, the regulatory roles of the remaining 9 miRNAs and miRNAs clusters have been undetermined. We could conclude that a majority of miRNAs show promoting role on apoptosis of FGCs in mammals. But the accurate mechanism of miRNAs and miRNA clusters have been not well understood.

\section{MOLECULAR SIGNALING PATHWAYS WERE SUMMARIZED}

The existence of miRNAs was discovered more than 20 years ago, and since then considerable achievements have been made in understanding the molecular mechanisms in the apoptosis, proliferation and development of follicular cells [78]. MiRNAs can combine with complementary sequences in the 5'-UTR [52] or 3'-UTR [21] of target mRNAs, therefore degrading the mRNA or repressing translation.

Nowadays, it has been known that many miRNAs modulate and FGCs apoptosis and follicular atresia through distinct signaling pathways [61]. Individual miRNAs target multiple genes and involve different patterns of pathways to regulate apoptosis of FGCs, follicular atresia and development. The miRNAs regulate varying signaling pathways of FGCs apoptosis and the ensuing FA via interacting with the mRNAs of target genes [37,58]. Several miRNAs targeting signaling pathways of FGCs apoptosis have been identified in bovine FGCs $[20,79]$. A previous report showed that at least 77 signaling pathways were reported in the documents which involved miRNAs regulation on FGCs apoptosis and FD [8]. Another study indicated 10 differentially expressed miRNAs and 117 pathways in dominant follicles were collected [51]. An earlier bioinformatic analysis of miRNAs expression of FGCs showed that 139 associated pathways were screened out during the growth and selection of dominant follicles [69]. Furthermore, Cha et al 83 reported that 48 signal transduction pathways are up-regulated by miRNAs and 29 pathways are downregulated by the miRNAs [80]. Nowdays, it has been clearly undetermined how many signal transduction pathways are involved in the miRNAs regulation roles $[8,64]$. Based on the 
Table 1. Regulatory roles of miRNAs on apoptosis of granulosa cells

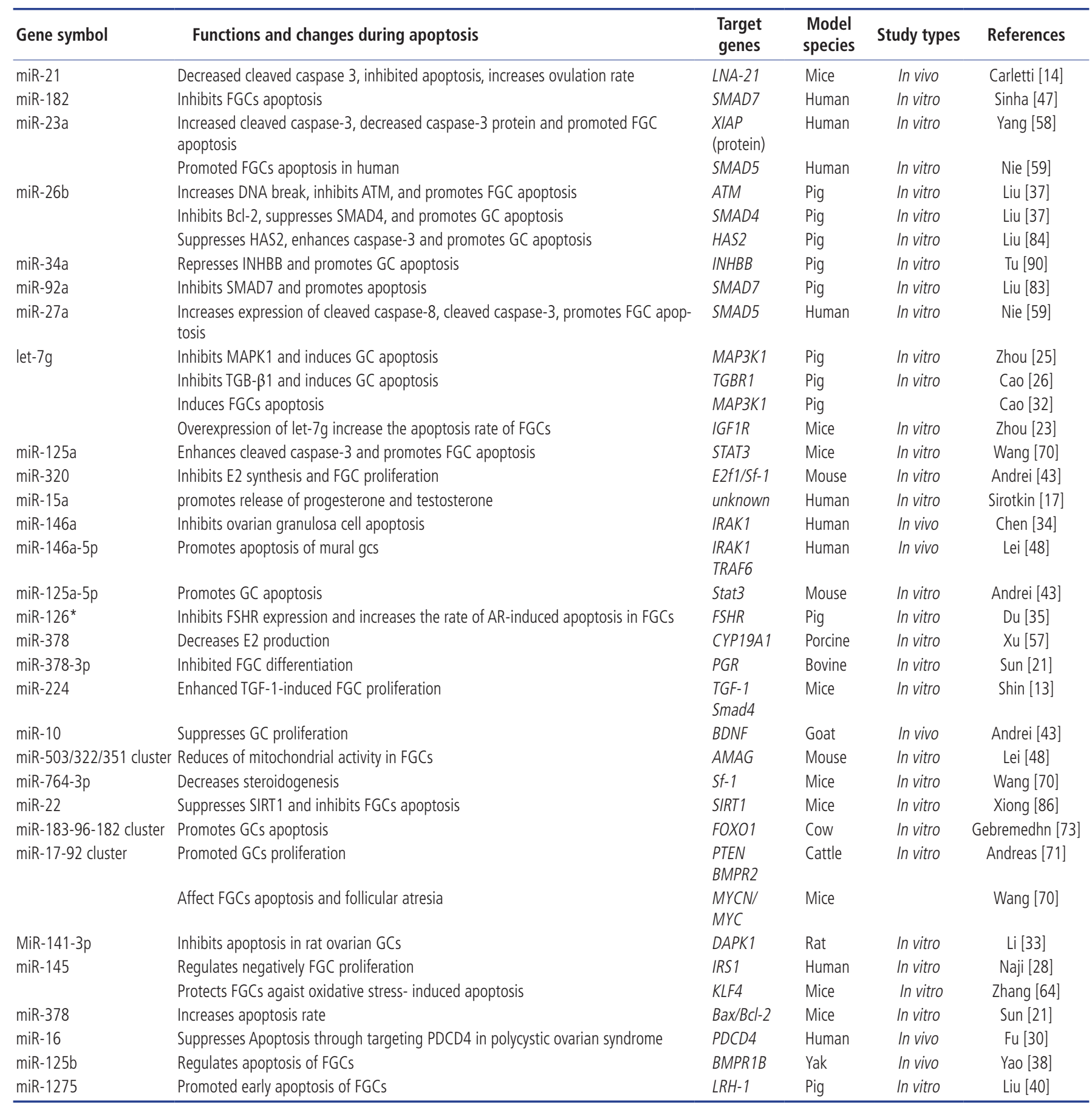

LNA-21, locked nucleic acid; FGCs, follicular granulosa cells; SMAD4, SMAD5, and SMAD7, Sma-and Mad-related 4, 5 and 7, respectively; XIAP, X-linked inhibitor of apoptosis protein; ATM, ataxia telangiectasia mutated gene; GCS, granulosa cells; HAS2, hyaluronic acid synthase 2; INHBB, inhibin beta-B; MAP3K1, mitogen-activated protein kinase kinase kinase 1; TGB- $\beta 1$, transforming growth factor- $\beta$ type 1; TGBR1, transforming growth factor- $\beta$ type 1 receptor; IGF1R, insulin-like growth factor 1 receptor; STAT3, signal transducer and activator of transcription 3; IRAK1, interleukin-1 receptor-associated kinase; TRAF6, tumor necrosis factor receptor-associated factor 6; FSHR, FSH receptor; CYP19A1, cytochrome P450, family 19, subfamily A, polypeptide 1; PGR, progesterone receptor; TGF-1, transforming growth factor 1; Smad2, Sma- and Mad-related protein 2; BDNF, brain derived neurotrophic factor; AMAG, autophagy/mitophagy-associated genes; Sf-1, steroidogenic factor-1; SIRT1, silent mating-type information regulation 2 homologue 1; FOX01, fork head 01; PTEN, phosphatase and tensin homolog deleted on chromosome ten; BMPR, bone morphogenetic protein receptor 1b; MYCNIMYC, Mycn proto-oncogene/Myc proto-oncogene; DAPK1, death-associated protein kinase 1; IRS1, insulin receptor substrate; KLF4, Krüppel-like factor 4; Bax/BCl-2, B-cell lymphoma-2 associated X/B-cell lymphoma-2; PDCD4, programmed cell death 4; BMPR1B, argeting bone morphogenetic protein receptor 1B; LRH-1, liver receptor homolog-1.

documents, partial miRNAs and their signal pathways are summarized in Table 2. As shown in this table, 16 miRNAs exert their functions by targeting 11 genes (mainly SMAD7) via mainly 11 signal pathways with the maximum of TGF- $\beta$ 
Table 2. miRNAs and their signal pathways

\begin{tabular}{|c|c|c|c|c|}
\hline Signal pathway & mi-RNAs & Target & Model Species & Reference \\
\hline \multirow[t]{7}{*}{ TGF- $\beta$} & miR-92a & SMAD7 & Mouse & Yang [55] \\
\hline & & & Human & Donadeu [56] \\
\hline & miR-181b & SMAD7 & Pig & Yao [38] \\
\hline & miR-let-7g & TGBR1 & Pig & Zhou [25] \\
\hline & miR-92a & SMAD7 & Pig & Liu [37] \\
\hline & miR-182 & SMAD7 & Rat & Luo [15] \\
\hline & miR-224 & SMAD4 & Mice & Yao [38] \\
\hline \multirow[t]{4}{*}{$\mathrm{BCl}-2$} & miR-26b & SMAD4 & Pig & Worku [49] \\
\hline & miR-26b & ATM & Pig & Liu [84] \\
\hline & miR-let-7g & МAP3K1 & Porcine & Cao [32] \\
\hline & miR-224 & SMAD4 & Pig & Liu [37] \\
\hline $\mathrm{BCl}-2 / \mathrm{Bax}$ & miR-125b & $B M P R 1 B$ & Yak & Yao [38] \\
\hline $\mathrm{BCl}-2 / \mathrm{MCL}-1$ & miR-let-7g & $T G B R 1$ & Pig & Cao [32] \\
\hline FasL-Fas & miR-23a miR-27a & SMAD5 & Human & Nie [59] \\
\hline TGFBR1 & miR-125b & SMAD7 & Pig & Yao [38] \\
\hline \multirow[t]{2}{*}{ HAS2-CDD44-casp-3 } & miR-26b & SMAD4 & Pig & Liu [84] \\
\hline & & USP9X & & Liu [37] \\
\hline HAS2-HA-cd44-casp-3 & miR-26b & HAS2 & Pig & Liu [84] \\
\hline sNPFR1/npyr & miR-9a & $N P Y 2 R$ & Porcine & Suh [54] \\
\hline MSK1 & miR-130 & SMAD5 & Cattle & Sinha [47] \\
\hline PKB/mTOR & miR-let-7g & IGF1R & Mice & Zhou [23] \\
\hline CP2/miR-144/COX-2/PGE2 & miR-144 & $C P 2$ & Mouse & Zhou [39] \\
\hline
\end{tabular}

TGF- $\beta$, transforming growth factor $\beta$; SMAD4, SMAD5, and SMAD7, Sma-and Mad-related 4, 5 and 7, respectively; TGBR1, transforming growth factor-beta type 1 receptor; BCl-2, B-cell lymphoma-2; ATM, ataxia telangiectasia mutated; MAP3K1, mitogen-activated protein kinase kinase kinase 1; BMPR1B, argeting bone morphogenetic protein receptor 1B; MCL-1, myeloid cell leukemia-1 gene; TGFBR1, threonine kinase complex composed of type l; HAS2, hyaluronan synthase 2; HA, hyaluronic acid; ubiquitin-specific proteases 9X (USP9X); sNPFR1, short neuropeptide F receptor 1; NPY2R, Neuropeptide Y receptor Y2; MSK1, mitogen- and stress-activated protein kinase 1; IGF1R, insulin-like growth factor 1 receptor; CP2, cyclooxygenase prostaglandin E2; COX, cyclooxygenase; PGE2, prostaglandin.

and Bcl-2 (Figure 1).

Moreover, the SMAD played an important role in regulating FD $[51,81]$. SMAD proteins can transduce the TGF- $\beta$ family signals at the cell surface into gene regulation in the nucleus. The miR-23a and miR-27a targeted SMAD5 and regulated apoptosis in human GCs via the FasL-Fas pathway [59].

The miR-224 and miR-26b regulate the pathway by targeting SMAD4 [13,82]. Earlier research indicated that miR$26 \mathrm{~b}$ was upregulated during porcine follicular atresia. In vitro

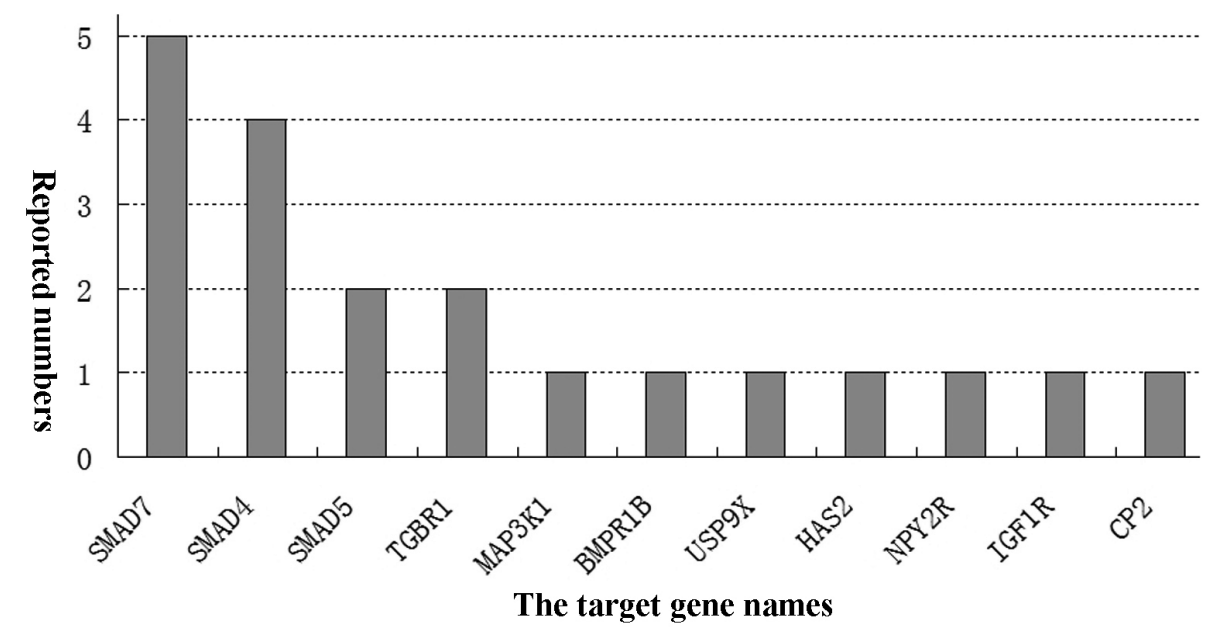

Figure 1. The main target genes and numbers of miRNAs regulatory roles on follicular granulosa cells (FGCS) apoptosis (articles published untill March 2019). The diverse types of miRNAs regulated FGCs apoptosis of and follicular development in humans and animals. But, which target gene is the key gene in these comprehensive processes so far has been undetermined. 
study revealed miR-26b enhanced DNA breaks and GC apoptosis by targeting ATM [83]. Overexpression of miR-26b in follicular FGCs suppressed levels of SMAD4 mRNA and protein, leading to down-regulation of the antiapoptosis $\mathrm{Bcl}-2$ gene and the promotion of GC apoptosis [49]. Another study reported that miR-26b and its overexpression could promote apoptosis of porcine FGCs by directly and indirectly targeting SMAD4, ubiquitin-specific proteases 9X and hyaluronic acid synthase 2 (HAS2) respectively [83]. The apoptosis processes are mediated through the HAS2-CDD44-Caspase-3 pathway [84]. These results strongly suggested that miR-26b plays a crucial role in GC apoptosis and follicular atresia.

The miR-23a and miR-27a promote human GC apoptosis by targeting SMAD5. Similarly, miR-92a, miR-181b, and miR-182 directly bind to SMAD7 [47,76], which is considered an antagonist of the TGF $\beta$ pathway [17] and an amplifier of TGF $\beta$-induced apoptosis [24]. Roles of the TGF $\beta$ pathway and related miRNA regulation have been frequently reported in recent years.

The functional networks play critical roles in the FD which contribute to the profound exploration on miRNAs roles. However, the association with downstream apoptosis genes and proteins remains still unclear $[85,86]$. The exact signal pathways in which the miRNAs exert need to be investigated in the future [40].

\section{CONCLUSIONS AND PERSPECTIVES}

MiRNAs are involved in physiological and developmental processes by post-transcriptionally inhibiting gene expression. In this review of 41 academic theses, we summarize the current advances in the regulatory roles of miRNAs and miRNA clusters on the FGCs apoptosis and FD in the mammals. Total of 30 miRNAs and 4 miRNAs clusters were reported in all articles. The documents indicated explicitly that 24 miRNAs and miRNAs clusters in 29 articles promoted or induced FGCs apoptosis through their distinctive target genes. The remaining 12 papers reported that 10 miRNAs and miRNAs clusters inhibited FGCs apoptosis. We could conclude that miRNAs or miRNAs clusters could modulate the apoptosis of GCs (including follicular GCs, mural GCs, and cumulus cells) by targeting its specific genes through the different signal pathway. A majority of miRNAs show promoting role on apoptosis of FGCs in mammals. But the accurate mechanism of miRNAs and miRNA clusters is not well understood $[8,43,64]$. The current results in the published documewnts are still not to clearly eaplain the distinctive effects of each miRNAs or miRNA cluster on FGCs apoptosis and FD in mamnals. It is extremely necessary to ascertain clearly the role and mechanism of each miRNA or miRNA cluster in the future. Understanding comprehensively mechanism of miRNA action may enhance the development of new tools to study miRNAs functions and inspire new diagnostic and treatment strategy or scheme for infertility [87], ovarian disorders and ovarian diseases associated to miRNA high expression or insufficiency [88], such as follicular infertility and ovarian cancer [89].

\section{AUTHOR CONTRIBUTIONS}

Professor Zhuandi Gong proposed the subject and designed the article. Dr. Xiaoyun Shen retrieved the references. Miss Juan Yang and Luju Lai analyzed the data of documents. Miss Bai Shengju drew the tables. Professor Suocheng Wei designed the article and wrote the manuscript.

\section{CONFLICT OF INTEREST}

We certify that there is no conflict of interest with any financial organization regarding the material discussed in the manuscript.

\section{ACKNOWLEDGMENTS}

The work was supported by the Innovative Team Development Project of Ministry of Education of China (IRT-17R88), the Reproductive Biotechnology Innovation Team of Animals of Colleges and Universities of Gansu Province of China (2017C-01) the innovative research team of Yak Reproductive Regulation Mecha $\neg$ nism and Plateau Adaptability (3192019 0024) and National Natural Science Foundation of the People's Republic of China (Grant No. 31460684, 41671041).

\section{REFERENCES}

1. Weixi X, Lin LY, Lili X, et al. Circulatory microRNA 23a and microRNA 23b and polycystic ovary syndrome (PCOS): the effects of body mass index and sex hormones in an Eastern Han Chinese population. J Ovarian Res 2017;10:10. https:// doi.org/10.1186/s13048-016-0298-8

2. Lau NC, Lim LP, Weinstein EG, Bartel DP. An abundant class of tiny RNAs with probable regulatory roles in Caenorhabditis elegans. Science 2001;294:858-62. https://doi.org/10.1126/ science. 1065062

3. Lee Y, Kim M, Han J, et al. MicroRNA genes are transcribed by RNA polymerase II. EMBO J 2004;23:4051-60. https://doi. org/10.1038/sj.emboj.7600385

4. Kozomara A, Griffiths-Jones S. miRBase: integrating microRNA annotation and deep-sequencing data. Nucleic Acids Res 2011;39(Suppl 1):D152-7. https://doi.org/10.1093/nar/ gkq1027

5. Filipowicz W, Bhattacharyya SN, Sonenberg N. Mechanisms of post-transcriptional regulation by microRNAs: are the answers in sight? Nat Rev Genet 2008;9:102-14. https://doi. 
org/10.1038/nrg2290

6. Yates LA, Norbury CJ, Gilbert RJC. The long and short of microRNA. Cell 2013;153:516-9. https://doi.org/10.1016/ j.cell.2013.04.003

7. Bhartiya D, James K. Very small embryonic-like stem cells (VSELs) in adult mouse uterine perimetrium and myometrium. J Ovarian Res 2017;10:29. https://doi.org/10.1186/s13048017-0324-5

8. Tesfaye D, Gebremedhn S, Salilew-Wondim D, et al. MicroRNAs: tiny molecules with a significant role in mammalian follicular and oocyte development. Reproduction 2018;155: R121-35. https://doi.org/10.1530/REP-17-0428

9. Grosshans H, Johnson T, Reinert KL, Gerstein M, Slack FJ. The temporal patterning microRNA let-7 regulates several transcription factors at the larval to adult transition in $C$. elegans. Dev Cell 2005;8:321-30. https://doi.org/10.1016/j. devcel.2004.12.019

10.Lockhart J, Canfield J, Mong EF, VanWye J, Totary-Jain H. Nucleotide modification alters microRNA-dependent silencing of microRNA switches. Mol Ther Nucleic Acids 2019;14: 339-50. https://doi.org/10.1016/j.omtn.2018.12.007

11. Mohr AM, Mott JL. Overview of microRNA biology. Semin Liver Dis 2015;35:3-11. https://doi.org/10.1055/s-0034-1397 344

12. Bartel DP. MicroRNAs: target recognition and regulatory functions. Cell 2009;136:215-33. https://doi.org/10.1016/ j.cell.2009.01.002

13. Shin C, Nam JW, Farh KK, Chiang HR, Shkumatava A, Bartel DP. Expanding the microRNA targeting code: functional sites with centered pairing. Mol Cell 2010;38:789-802. https:// doi.org/10.1016/j.molcel.2010.06.005

14. Carletti MZ, Fiedler SD, Christenson LK. MicroRNA 21 blocks apoptosis in mouse periovulatory granulosa cells. Biol Reprod 2010;83:286-95. https://doi.org/10.1095/biolreprod.109.081 448

15. Luo M, Li L, Xiao C, Sun Y, Wang GL. Heat stress impairs mice granulosa cell function by diminishing steroids production and inducing apoptosis. Mol Cell Biochem 2016;412:81-90. https://doi.org/10.1007/s11010-015-2610-0

16. Aherne ST, Lao NT. Manipulating miRNA expression to uncover hidden functions. Methods Mol Biol (Clifton, NJ). 2017;1509:151-60. https://doi.org/10.1007/978-1-4939-65243_14

17.Sirotkin AV, Laukova M, Ovcharenko D, Brenaut P, Mlyncek M. Identification of microRNAs controlling human ovarian cell proliferation and apoptosis. J Cell Physiol 2010;223:4956. https://doi.org/10.1002/jcp.21999

18. Dai A, Sun H, Fang T, et al. MicroRNA-133b stimulates ovarian estradiol synthesis by targeting Foxl2. FEBS Lett 2013;587: 2474-82. https://doi.org/10.1016/j.febslet.2013.06.023

19. Kitahara Y, Nakamura K, Kogure K, Minegishi T. Role of microRNA-136-3p on the expression of luteinizing hormone- human chorionic gonadotropin receptor mRNA in rat ovaries. Biol Reprod 2013;89:114. https://doi.org/10.1095/biolreprod. 113.109207

20.Gebremedhn S, Salilew-Wondim D, Ahmad I, et al. MicroRNA expression profile in bovine granulosa cells of preovulatory dominant and subordinate follicles during the late follicular phase of the estrous cycle. PloS one 2015;10:e0125912. https://doi.org/10.1371/journal.pone.0125912

21.Sun XF, Li YP, Pan B. Molecular regulation of miR-378 on the development of mouse follicle and the maturation of oocyte in vivo. Cell Cycle (Georgetown, Tex). 2018;17:223042. https://doi.org/10.1080/15384101.2018.1520557

22. Aherne ST, Lao NT. Manipulating miRNA expression to uncover hidden functions. In: Rani S, editor. MicroRNA profiling. Methods in Molecular Biology. New York, NY, USA: Humana Press; 2017. vol 1509 pp. 151-60. https://doi.org/10. 1007/978-1-4939-6524-3_14

23.Zhou J, Yao W, Liu K, et al. MicroRNA let-7g regulates mouse granulosa cell autophagy by targeting insulin-like growth factor 1 receptor. Int J Biochem Cell Biol 2016;78:130-40. https://doi.org/10.1016/j.biocel.2016.07.008

24. Su JL, Chen PS, Johansson G, Kuo ML. Function and regulation of let-7 family microRNAs. MicroRNA 2012;1:34-9.

25.Zhou J, Liu J, Pan Z, et al. The let-7g microRNA promotes follicular granulosa cell apoptosis by targeting transforming growth factor-beta type 1 receptor. Mol Cell Endocrinol 2015; 409:103-12. https://doi.org/10.1016/j.mce.2015.03.012

26. Cao R, Wu WJ, Zhou XL, Xiao P, Wang Y, Liu HL. Expression and preliminary functional profiling of the let-7 family during porcine ovary follicle atresia. Mol Cells 2015;38:304-11. https:// doi.org/10.14348/molcells.2015.2122

27. Cao R, Wu W, Zhou X, et al. Let-7g induces granulosa cell apoptosis by targeting MAP3K1 in the porcine ovary. Int J Biochem Cell Biol 2015;68:148-57. https://doi.org/10.1016/ j.biocel.2015.08.011

28. Naji M, Aleyasin A, Nekoonam S, Arefian E, Mahdian R. Differential Expression of miR-93 and miR-21 in granulosa cells and follicular fluid of polycystic ovary syndrome associating with different phenotypes. Sci Rep 2017;7:14671. https://doi. org/10.1038/s41598-017-13250-1

29.Han X, Xue R, Yuan HJ, et al. MicroRNA-21 plays a pivotal role in the oocyte-secreted factor-induced suppression of cumulus cell apoptosis. Biol Reprod 2017;96:1167-80. https:// doi.org/10.1093/biolre/iox044

30.Fu X, He Y, Wang X, et al. Overexpression of miR-21 in stem cells improves ovarian structure and function in rats with chemotherapy-induced ovarian damage by targeting PDCD4 and PTEN to inhibit granulosa cell apoptosis. Stem Cell Res Therapy 2017;8:187. https://doi.org/10.1186/s13287-0170641-z

31.Tscherner A, Brown AC, Stalker L, et al. STAT3 signaling stimulates miR-21 expression in bovine cumulus cells during 
in vitro oocyte maturation. Sci Rep 2018;8:11527. https://doi. org/10.1038/s41598-018-29874-w

32. Cao C, Ding Y, Kong X, et al. Reproductive role of miRNA in the hypothalamic-pituitary axis. Mol Cell Neurosci 2018; 88:130-7. https://doi.org/10.1016/j.mcn.2018.01.008

33.Li X, Jin Y, Mu Z, Chen W, Jiang S. MicroRNA146a5p enhances cisplatininduced apoptosis in ovarian cancer cells by targeting multiple antiapoptotic genes. Int J Oncol 2017;51:327-35. https://doi.org/10.3892/ijo.2017.4023

34. Chen X, Xie M, Liu D, Shi K. Downregulation of microRNA146a inhibits ovarian granulosa cell apoptosis by simultaneously targeting interleukin-1 receptor-associated kinase and tumor necrosis factor receptor-associated factor 6. Mol Med Rep 2015;12:5155-62. https://doi.org/10.3892/mmr.2015. 4036

35.Du X, Li Q, Pan Z, Li Q. Androgen receptor and miRNA-126* axis controls follicle-stimulating hormone receptor expression in porcine ovarian granulosa cells. Reproduction 2016;152: 161-9. https://doi.org/10.1530/REP-15-0517

36.Li D, Xu D, Xu Y, et al. MicroRNA-141-3p targets DAPK1 and inhibits apoptosis in rat ovarian granulosa cells. Cell Biochem Funct 2017;35:197-201. https://doi.org/10.1002/ cbf. 3248

37.Liu J, Du X, Zhou J, Pan Z, Liu H, Li Q. MicroRNA-26b functions as a proapoptotic factor in porcine follicular Granulosa cells by targeting Sma-and Mad-related protein 4. Biol Reprod 2014;91:146. https://doi.org/10.1095/biolreprod.114.122788

38. Yao YL, Niu JQ, Sizhu SL, et al. microRNA-125b regulates apoptosis by targeting bone morphogenetic protein receptor 1B in yak granulosa cells. DNA Cell Biol 2018;37:878-87. http:// doi.org/10.1089/dna.2018.4354

39.Zhou J, Lei B, Li H, et al. MicroRNA-144 is regulated by CP2 and decreases COX-2 expression and PGE2 production in mouse ovarian granulosa cells. Cell Death Disease 2017;8: e2597. https://doi.org/10.1038/cddis.2017.24

40.Liu J, Li X, Yao Y, Li Q, Pan Z, Li Q. miR-1275 controls granulosa cell apoptosis and estradiol synthesis by impairing LRH-1/CYP19A1 axis. Biochim Biophys Acta Gene Regul Mech 2018;1861:246-57. https://doi.org/10.1016/j.bbagrm. 2018.01.009

41.Ikeda S, Imai H, Yamada M. Apoptosis in cumulus cells during in vitro maturation of bovine cumulus-enclosed oocytes. Reproduction 2003;125:369-76.

42. Atwood CS, Vadakkadath Meethal S. The spatiotemporal hormonal orchestration of human folliculogenesis, early embryogenesis and blastocyst implantation. Mol Cell Endocrinol 2016;430:33-48. https://doi.org/10.1016/j.mce.2016.03.039

43. Andrei D, Nagy RA, van Montfoort A, et al. Differential miRNA expression profiles in cumulus and mural granulosa cells from human pre-ovulatory follicles. MicroRNA (Shariqah, United Arab Emirates). 2019;8:61-7. https://doi.org/10.2174/ 2211536607666180912152618
44. Chang HM, Qiao J, Leung PC. Oocyte-somatic cell interactions in the human ovary-novel role of bone morphogenetic proteins and growth differentiation factors. Hum Reprod Update 2016;23:1-18. https://doi.org/10.1093/humupd/dmw039

45. Wigglesworth K, Lee KB, Emori C, Sugiura K, Eppig JJ. Transcriptomic diversification of developing cumulus and mural granulosa cells in mouse ovarian follicles. Biol Reprod 2015; 92:23. https://doi.org/10.1095/biolreprod.114.121756

46. Tesfaye D, Worku D, Rings F, et al. Identification and expression profiling of microRNAs during bovine oocyte maturation using heterologous approach. Mol Reprod Dev 2009;76:66577. https://doi.org/10.1002/mrd.21005

47.Sinha PB, Tesfaye D, Rings F, et al. MicroRNA-130b is involved in bovine granulosa and cumulus cells function, oocyte maturation and blastocyst formation. J Ovarian Res 2017;10:37. https://doi.org/10.1186/s13048-017-0336-1

48.Lei L, Jin SY, Gonzalez G, Behringer RR, Woodruff TK. The regulatory role of Dicer in folliculogenesis in mice. Mol Cell Endocrinol 2010;315:63-73. https://doi.org/10.1016/j.mce. 2009.09.021

49.Worku T, Rehman ZU, Talpur HS, et al. MicroRNAs: New insight in modulating follicular atresia: a review. Int J Mol Sci 2017;18:333. https://doi.org/10.3390/ijms18020333

50.Jiao J, Shi B, Wang T, et al. Characterization of long noncoding RNA and messenger RNA profiles in follicular fluid from mature and immature ovarian follicles of healthy women and women with polycystic ovary syndrome. Hum Reprod 2018;33:1735-48. https://doi.org/10.1093/humrep/dey255

51.Zhang B, Chen L, Feng G, et al. MicroRNA mediating networks in granulosa cells associated with ovarian follicular development. BioMed Res Int 2017;2017:4585213. https:// doi.org/10.1155/2017/4585213

52. Orom UA, Nielsen FC, Lund AH. MicroRNA-10a binds the 5'UTR of ribosomal protein mRNAs and enhances their translation. Mol Cell 2008;30:460-71. https://doi.org/10.1016/j. molcel.2008.05.001

53. Yan G, Zhang L, Fang T, et al. MicroRNA-145 suppresses mouse granulosa cell proliferation by targeting activin receptor IB. FEBS Lett 2012;586:3263-70. https://doi.org/10.1016/j.febslet. 2012.06.048

54.Suh YS, Bhat S, Hong SH, et al. Genome-wide microRNA screening reveals that the evolutionary conserved miR-9a regulates body growth by targeting sNPFR1/NPYR. 2015;6: 7693. https://doi.org/10.1038/ncomms8693

55. Yang S, Wang S, Luo A, et al. Expression patterns and regulatory functions of microRNAs during the initiation of primordial follicle development in the neonatal mouse ovary. Biol Reprod 2013;89:126. https://doi.org/10.1095/biolreprod.113.107730

56. Donadeu FX, Schauer SN, Sontakke SD. Involvement of miRNAs in ovarian follicular and luteal development. J Endocrinol 2012;215:323-34. https://doi.org/10.1530/joe-12-0252

57.Xu S, Linher-Melville K, Yang BB, Wu D, Li J. Micro-RNA378 
(miR-378) regulates ovarian estradiol production by targeting aromatase. Endocrinology 2011;152:3941-51. https://doi.org/ 10.1210/en.2011-1147

58. Yang X, Zhou Y, Peng S, et al. Differentially expressed plasma microRNAs in premature ovarian failure patients and the potential regulatory function of mir-23a in granulosa cell apoptosis. Reproduction 2012;144:235-44. https://doi.org/10. 1530/REP-11-0371

59. Nie M, Yu S, Peng S, Fang Y, Wang H, Yang X. miR-23a and miR-27a promote human granulosa cell apoptosis by targeting SMAD5. Biol Reprod 2015;93:98. https://doi.org/10.1095/ biolreprod.115.130690

60. Huang X, Liu C, Hao C, et al. Identification of altered microRNAs and mRNAs in the cumulus cells of PCOS patients: miRNA-509-3p promotes oestradiol secretion by targeting MAP3K8. Reproduction 2016;151:643-55. https://doi.org/ 10.1530/REP-16-0071

61.Donadeu FX, Mohammed BT, Ioannidis J. A miRNA target network putatively involved in follicular atresia. Domest Anim Endocrinol 2017;58:76-83. https://doi.org/10.1016/j.domani end.2016.08.002

62. O'Doherty AM, O'Brien YM, Browne JA, Wingfield M, O'Shea LC. Expression of granulosa cell microRNAs, AVEN and ATRX are associated with human blastocyst development. Mol Reprod Dev 2018;85:836-48. https://doi.org/10.1002/ mrd.22990

63. Lee J, Park H, Eom J, Kang SG. MicroRNA-mediated regulation of the development and functions of follicular helper $\mathrm{T}$ cells. Immune Netw 2018;18:e7. https://doi.org/10.4110/in. 2018.18.e7

64.Zhang J, Xu Y, Liu H, Pan Z. MicroRNAs in ovarian follicular atresia and granulosa cell apoptosis. Reprod Biol Endocrinol 2019;17:9. https://doi.org/10.1186/s12958-018-0450-y

65. Inoue $\mathrm{K}$, Hirose $\mathrm{M}$, Inoue $\mathrm{H}$, et al. The rodent-specific microRNA cluster within the Sfmbt2 gene is imprinted and essential for placental development. Cell Rep 2017;19:949-56. https:// doi.org/10.1016/j.celrep.2017.04.018

66. Schauer SN, Sontakke SD, Watson ED, Esteves CL, Donadeu FX. Involvement of miRNAs in equine follicle development. Reproduction 2013;146:273-82. https://doi.org/10.1530/ REP-13-0107

67. Battaglia R, Vento ME, Ragusa M, et al. MicroRNAs are stored in human MII oocyte and their expression profile changes in reproductive aging. Biol Reprod 2016;95:131. https://doi. org/10.1095/biolreprod.116.142711

68. Saliminejad K, Khorram Khorshid HR, Soleymani Fard S, Ghaffari SH. An overview of microRNAs: Biology, functions, therapeutics, and analysis methods. J Cell Physiol 2019;234: 5451-65. https://doi.org/10.1002/jcp.27486

69.Li X, Zhuang X, Xu T, et al. Expression analysis of microRNAs and mRNAs in ovarian granulosa cells after microcystin-LR exposure. Toxicon 2017;129:11-9. https://doi.org/10.1016/j. toxicon.2017.01.022

70. Wang J, Xu B, Tian GG, Sun T, Wu J. Ablation of the MiR17-92 MicroRNA cluster in germ cells causes subfertility in female mice. Cell Physiol Biochem 2018;45:491-504. https:// doi.org/10.1159/000487028

71. Andreas E, Hoelker M, Neuhoff C, et al. MicroRNA 17-92 cluster regulates proliferation and differentiation of bovine granulosa cells by targeting PTEN and BMPR2 genes. Cell Tissue Res 2016;366:219-30. https://doi.org/10.1007/s00441016-2425-7

72.Li P, Sheng C, Huang L, et al. MiR-183/-96/-182 cluster is up-regulated in most breast cancers and increases cell proliferation and migration. Breast Cancer Res 2014;16:473. https:// doi.org/10.1186/s13058-014-0473-Z

73. Gebremedhn S, Salilew-Wondim D, Hoelker M, et al. MicroRNA-183-96-182 cluster regulates bovine granulosa cell proliferation and cell cycle transition by coordinately targeting FOXO1. Biol Reprod 2016;94:127. https://doi.org/10.1095/ biolreprod.115.137539

74. Herndon MK, Law NC, Donaubauer EM, Kyriss B, HunzickerDunn M. Forkhead box O member FOXO1 regulates the majority of follicle-stimulating hormone responsive genes in ovarian granulosa cells. Mol Cell Endocrinol 2016;434: 116-26.

75. Askandar Iqbal M, Arora S, Prakasam G, Calin GA, Syed MA. MicroRNA in lung cancer: role, mechanisms, pathways and therapeutic relevance. Mol Aspects Med 2019;70:3-20. https:// doi.org/10.1016/j.mam.2018.07.003

76. Shippy DC, Bearson BL, Cai G, Brunelle BW, Kich JD, Bearson SMD. Modulation of porcine microRNAs associated with apoptosis and NF-kappaB signaling pathways in response to Salmonella enterica serovar Typhimurium. Gene 2018;676: 290-7. https://doi.org/10.1016/j.gene.2018.08.044

77. Mendell JT. miRiad roles for the miR-17-92 cluster in development and disease. Cell 2008;133:217-22. https://doi.org/10. 1016/j.cell.2008.04.001

78. Thomson DW, Dinger ME. Endogenous microRNA sponges: evidence and controversy. Nat Rev Genet 2016;17:272-83. https://doi.org/10.1038/nrg.2016.20

79. Silveira Zavalhia L, Weber Medeiros A, Oliveira Silva A, Vial Roehe A. Do FHIT gene alterations play a role in human solid tumors? 2018;14:e214-23. https://doi.org/10.1111/ajco.12868

80. Cha HJ, An SK, Kim TJ, Lee JH. Alteration of microRNA profiling in sphere-cultured ovarian carcinoma cells. Oncol Lett 2018;16:2016-22. https://doi.org/10.3892/ol.2018.8818

81. Richards JS. From follicular development and ovulation to ovarian cancers: an unexpected journey. Vitam Horm 2018; 107:453-72. https://doi.org/10.1016/bs.vh.2018.01.019

82. Shi L, Liu S, Zhao W, Shi J. miR-483-5p and miR-486-5p are down-regulated in cumulus cells of metaphase II oocytes from women with polycystic ovary syndrome. Reprod Biomed Online 2015;31:565-72. https://doi.org/10.1016/j.rbmo.2015. 
06.023

83. Liu J, Yao W, Yao Y, et al. MiR-92a inhibits porcine ovarian granulosa cell apoptosis by targeting Smad7 gene. FEBS Lett 2014;588:4497-503. https://doi.org/10.1016/j.febslet.2014. 10.021

84. Liu J, Tu F, Yao W, et al. Conserved miR-26b enhances ovarian granulosa cell apoptosis through HAS2-HA-CD44-Caspase-3 pathway by targeting HAS2. Sci Rep 2016;6:21197. https:// doi.org/10.1038/srep21197

85.Li Y, Ganta S, Cheng C, Craig R, Ganta RR, Freeman LC. FSH stimulates ovarian cancer cell growth by action on growth factor variant receptor. Mol Cell Endocrinol 2007;267:2637. https://doi.org/10.1016/j.mce.2006.11.010

86. Xiong F, Hu L, Zhang Y, Xiao X, Xiao J. miR-22 inhibits mouse ovarian granulosa cell apoptosis by targeting SIRT1. Biol Open 2016;5:367-71. https://doi.org/10.1242/bio.016907
87.Eisenberg I, Nahmias N, Novoselsky Persky M, et al. Elevated circulating micro-ribonucleic acid (miRNA)-200b and miRNA-429 levels in anovulatory women. Fertil Ssteril 2017; 107:269-75. https://doi.org/10.1016/j.fertnstert.2016.10.003

88. Rios C, Warren D, Olson B, Abbott AL. Functional analysis of microRNA pathway genes in the somatic gonad and germ cells during ovulation in C. elegans. Dev Biol 2017;426:11525. https://doi.org/10.1016/j.ydbio.2017.04.007

89. Wei J, Zhang L, Li J, et al. Microrna-205 promotes cell invasion by repressing tcf 21 in human ovarian cancer. J Ovarian Res 2017;10:33-8. https://doi.org/10.1186/s13048-017-0328-1

90.Tu F, Pan ZX, Yao Y, et al. miR-34a targets the inhibin beta B gene, promoting granulosa cell apoptosis in the porcine ovary. Genet Mol Res GMR. 2014;13:2504-12. https://doi.org/10. 4238/2014.January.14.6 